Original Research Paper

\title{
One can Achieve the Nuclear Fission Reaction of Lithium by Accelerated Hydrogen Nuclei or Neutrons
}

\author{
Relly Victoria Virgil Petrescu and Florian Ion Tiberiu Petrescu \\ ARoTMM-IFToMM, Bucharest Polytechnic University, Bucharest, (CE), Romania
}

\author{
Article history \\ Received: 08-05-2021 \\ Revised: 07-08-2021 \\ Accepted: 26-06-2021 \\ Corresponding Author \\ R.V.V. Petrescu \\ ARoTMM-IFToMM, Bucharest \\ Polytechnic University, \\ Bucharest, (CE), Romania \\ Email: rvvpetrescu@gmail.com
}

\begin{abstract}
The idea circulated among physicists that in the upper area of the physical elements the fission reaction can be obtained and in the lower one the fusion reaction occurs. In the presented paper we want to impose another rule, namely the obtaining in the lower part of the physical elements of the fission and fusion nuclear reactions, with the obvious purpose of obtaining free nuclear energy on an industrial scale. The advantages of using the low area of the physical and chemical elements are multiple. For example, in this area there are no spontaneous reactions, nor disintegrations, so the nuclear fuel used will be without radioactivity and usually, the result of the reaction will also be without radioactive components, so there will be no nuclear residues in the reaction radioactive. In this way, no such nuclear residues remain after such reactions that need to be processed or buried somewhere. Basically, this is a huge advantage of the nuclear exploitation of the low-element area. Another immediate advantage is the use of renewable and sustainable fuel, because, in the high area of heavy physical elements, those used as nuclear fuel are already beginning to run out. Here in the low area of the physicochemical elements the elements are found quite frequently naturally, or can be obtained by various methods, so the nuclear fuels in this area are sustainable, which is a second great advantage in the production of nuclear energy on the industrial route. The third great advantage of using nuclear fuels in the area of low elements (light, low mass) is that nuclear fission or fusion reactions are easily controllable in this area and they have virtually no way to get out of control and produce unwanted (accidental) events. The paper briefly presents an original theoretical method that aims to obtain nuclear energy by forcing a good efficiency of the reaction between lithium and hydrogen by accelerating hydrogen nuclei to energies high enough to cover the kinetic energy of an accelerated proton so that it to overcome the potential nuclear energy barrier of rejection between the charges of the same kind of lithium nucleus and proton, considering the most unfavorable situation possible when the proton approaches the lithium nucleus to its positively charged part through its three protons. It is hoped that in this way a general laboratory reaction, lithium-proton, can be performed continuously. Basically, the paper proposes to replace the classic nuclear fission reactions that use as enriched uranium fuel and lithium catalyst, with the industrial nuclear fission reaction of lithium (lithium changes from the position of catalyst to that of nuclear fuel), so that its new fission reaction be better controlled, less dangerous and almost free of radioactive waste as is the case with uranium fission.
\end{abstract}

Keywords: Lithium, Fission Energy, Nuclear Energy, Condensed Matter, Nuclear power, Nuclear Fusion, Accelerated Particles 


\section{Introduction}

Being practically the lightest metal, i.e., the first in Mendeleev's well-known table, Lithium and the element of atomic number 3 , it is practically extremely versatile, already having extremely many applications, starting from medical and continuing with those in the fields of physics. Then in the electronics industry, today lithium has become practically the key element for modern batteries and accumulators used almost everywhere. In medicine, lithium carbonate is needed to treat some types of bipolar disorder, to help stabilize changes in conditions that may occur from these conditions. Today, lithium is part of the important alloys for the car manufacturing industry and especially the aerospace industry, in the manufacture of aircraft and other vehicles. Lithium already has a diverse and bushy history. The first to discover lithium was the Brazilian naturalist Jozé Bonifácio de Andralda e Silva, who found the mineral petalite ( $\left.\mathrm{LiAlSi}_{4} \mathrm{O} 10\right)$ on the Swedish island of Utö around the end of the 18th century. This mineral has a white to gray color, but when thrown into the fire the flames it develops take on a bright cherry-like color. In 1817 the Swedish chemist Johan August Arfwedson was able to prove that the petalite contains an element unknown until then and although in the first phase he could not completely isolate the lithium metal, he was still able to isolate one of its salts. The name lithium derives from "lithos", a Greek word meaning "stone". It took some time before lithium, the metal that has the most uses today, could be completely isolated, in 1855 when lithium could be isolated by chemists Augustus Matthiessen and Robert Bunsen who passing an electric current through a chloride. lithium, managed in this way to separate the element lithium, the element with atomic number (number of protons in the nucleus) 3, the atomic symbol in the periodic table of elements $\mathrm{Li}$, having atomic mass 6,941, density 0.534 grams per cubic centimeter, state of aggregation at room temperature being the solid one, with the melting point of 180.5 degrees Celsius and with the boiling point at 1342 degrees Celsius. The number of isotopes (atoms of the same element with a different number of neutrons), being 10, but only two of them being stable: Li-7 and Li-6, so the only ones used frequently. It can be said that lithium is a special metal in many ways because it becomes light and soft, can be cut with a kitchen knife and having so little density that it can float on water, lithium having one of the lowest temperatures melting, but a very high boiling point. Similar to sodium (also an alkaline) and lithium reacts immediately and strongly with water, by the reaction between $\mathrm{Li}$ and $\mathrm{H}_{2} \mathrm{O}$ forming lithium hydroxide and hydrogen, which generates a red flame, so in this way the lithium metal becomes a carrier and storage of hydrogen on which will release it when it comes in contact with water, thus becoming a valuable fuel for the aerospace industry that needs hydrogen fuel stored in and through solid lithium instead of keeping liquid hydrogen or very high pressure in honeycomb devices with multiple cells .Pure lithium is actually an extremely rare metal, forming only $0.0007 \%$ of the earth's crust and cannot be found freely, but only combined in minerals and salts. Salts (which have the ability to change the structure and functionality of the brain which is an aqueous structure) being in fact the first drugs that were approved by the "Food and Drug Administration" to treat mania and depression, so that today most commonly sold the drug. Although the mechanisms by which lithium manages to stabilize mood are not yet known, it is widely used for this purpose in psychiatric medicine because clinical studies show several favorable effects on the central nervous system following the use of lithium. As an example, a group of researchers spoke in 2009 in the journal Cell that lithium can disrupt the activity of a dopamine receptor neurotransmitter. In addition, it increases the volume of the brain, a fact never seen before in other substances, according to a 2011 study published in Biological Psychiatry. Another paper published in 2016 in Current Biology indicates that lithium can make certain neurons calm down, so lithium has a calming effect on the central nervous system. Together with the first and second element, hydrogen and helium, lithium makes up a triad of elements (the lightest) that were created at the birth of the Universe by the Big Bang or whatever it was created, although according to the Big Bang theory our universe would be it had to contain at least for three times as much lithium. This issue of lack of lithium in the universe has troubled the minds of astrophysicists since the 1980s, until recently in August 2018 when an article appeared in Nature Astronomy describing a massive lithium discovery in a giant star where it is found in a concentration 3,000 times higher than that known in the cosmos and on Earth today. It was assumed that the lithium could have come either from the planets swallowed by the giant star or through an internal process still unknown to us. However, it is the first step in developing an explanation for the "lithium deficiency problem". Lithium reacting very easily, it could react in time so that it is no longer generally free today in large quantities. Today, lithium is the basic element of batteries and accumulators, at least until the discovery of another type of battery or accumulator. Lithium and its compounds have many industrial applications today, including the manufacture of heatresistant glass and ceramics, lithium-based lubricants, additives used in the production of iron, steel and aluminum, lithium-based batteries and lithium ions. All 
these uses today consume more than $3 / 4$ of lithium production. There are generally small amounts of lithium in all organisms. Due to its high reactivity, lithium cannot generally be found in free form in nature but is present in the form of ionic compounds. Lithium is a constituent of some pegmatitic minerals and due to its ionic solubility is present in ocean water and can be obtained from brines and clays. Today, on a commercial scale, lithium is electrolytically isolated using a mixture of lithium chloride and potassium chloride .As we have already shown, even though lithium is abundant on Earth, it does not occur naturally in elemental form due to its high reactivity, but the total lithium content in sea and ocean water is very high, estimated at about 230 billion tons, the element existing at a relatively constant concentration of 0.14 to 0.25 Parts Per Million (ppm) or 25 micromolar, while some concentrations higher than $7 \mathrm{ppm}$ may be near the hydrothermal vents (Lithium Occurrence, 2009). In other words, even though it is not found in nature and on our planet, in combinations it is in very large quantities and can therefore be easily obtained today on a large scale, which is already recommended for its many industrial applications in electronics, accumulators and batteries, various chemical reactions and on a medium scale to some drugs. Lithium is sometimes added to gases to generate a red flame. It has been used in the past to support thermonuclear reactions, but unfortunately only in the manufacture of such bombs. It is already proposed as an adjunct or catalyst for the cold or hot fusion nuclear reaction, but as the fusion reaction is not yet performed on an industrial scale, lithium does not yet have a massive use here. It is hoped that, in the near future, it will be possible to obtain nuclear fusion energy, in which lithium will also play an important role (Petrescu and Petrescu, 2019a-b; 2018; Petrescu, 2019; 2018; Petrescu and Calautit, 2016; Petrescu et al., 2019, 2017a-f; 2016; World Nuclear Association, 2017). Lithium-7 already has two basic uses in nuclear energy today due to the relative transparency of neutrons. In the form of hydroxide, it is needed only in small quantities in order to ensure the correct operation of cooling systems from Pressurized Water Reactors (PWR) as a $\mathrm{pH}$ stabilizer where it reduces corrosion in the primary circuit. Lithium will have a much higher demand for Molten Salt (MSR) reactors, such as those with fluorine. In both cases, it will be used only as a very pure Li-7. An amount of $99.95 \% \mathrm{Li}-7$ hydroxide is used in nuclear energy engineering as an additive in the PWR primary coolant at about $2.2 \mathrm{ppm}$ to maintain the water chemistry by counteracting the corrosive effects of boric acid (used as an absorbent of neutrons) and to minimize corrosion in PWR steam generators. Lithium is also used in the preparation of chemical reagents needed in nuclear energy engineering and as a basic component in the preparation of nuclear ion exchange membranes used in PWR cooling water treatment plants. Lithium 7 is extremely necessary due to its very small neutron cross-section $(0.045)$ when using nuclear energy. Today in the US there is some concern (concern) about the supply of Li-7, in December 2013 the Institute of Nuclear Energy stated that the critical supply situation with Li-7 highlighted the importance of monitoring all aspects of the nuclear supply chain, given that approximately 400 $\mathrm{kg} /$ year Li-7 is required for PWR reactors in the US alone. The second important situation (category) that I mentioned earlier is the one in which it is found as fluorine when Li-7 is then used in Lithium Fluoride (LiF) and in lithium beryllium fluoride (FLiBe), which are contained in the cooling salt of most Molten Salt Reactors (MSR), which are today at the center of intensive development. FLiBe contains about $14 \%$ lithium, so much higher levels of purity are required $-99.995 \%$ Li-7. In most situations the cooling salt also has the fuel dissolved in it, such fluoride salts having a very low vapor pressure even at red heat, they carry more heat than the same volume of water, generally possess better properties heat transfer, also achieving a lower absorption of neutrons, a way in which they are not damaged by radiation and do not react violently with air or water, some of them being inert to some common structural metals. The LiF compound is extremely chemically stable, while the LiF-BeF2 mixture ("FLiBe") is eutectic (at $459^{\circ} \mathrm{C}$ it has a lower melting point than any of the ingredients $-\mathrm{LiF}$ is about $500^{\circ} \mathrm{C}$ ). FLiBe is favorable in the primary cooling of MSR and when it is uncontaminated it also produces a low corrosion effect. It is known that the three nuclides ( $\mathrm{Li}-7, \mathrm{Be}, \mathrm{F})$ are among the very few that have cross-sections of thermal neutron capture they are low enough not to interfere with fission reactions. As FLiNaK (LiF-NaF-KF) is also a eutectic that solidifies at $454^{\circ} \mathrm{C}$, it has virtually a higher section of neutrons than FLiBe or LiF, but can be used in intermediate cooling loops (without toxic beryllium) (Petrescu and Petrescu, 2020a). Although more present in the earth's crust in relatively small quantities, lithium is still not a rare metal. Lithium, as I originally said, comes from the name of the ancient Greek rock or stone, can be found in a number of minerals found in acidic igneous rocks, such as granite and pegmatites, spodumene and petalite (these being the most common sources of minerals). Due to the high solubility of lithium-ion is present in the water of the oceans and seas in very large quantities, being frequently obtained from brine and clays (hectorite). In the earth's crust, lithium is the 25th most abundant element. Today all lithium carbonate prices have been stable at about $\$ 4700$ per tonne, but when they are reported they are around $\$ 9,000$ per tonne (so you can see from here not practically a lack of lithium on our planet as its growing need in its various industrial uses and perhaps the largest lithium-consuming industry that has surpassed the nuclear one of the moment is the manufacture of today's batteries and accumulators that 
appear almost everywhere). In addition, according to some studies (estimates), the demand for lithium carbonate $(19 \% \mathrm{Li})$ is still expected to increase soon from 165,000 tons in 2015 to over 500,000-600,000 tons by 2025. According to estimates made by the United States Geological Survey (USGS) and subsequently modified by Geoscience Australia for Australia's resources, all lithium resources up to 2012 totaled about 13.5 million tons. Chile has about $7.5 \mathrm{Mt}$, or about $56 \%$ of total world resources, followed immediately by China with $3.5 \mathrm{Mt}$ (about 26\%), then Australia with 1.5 Mt (11.4\%) and finally Argentina with $0.85 \mathrm{Mt}$ (6.3\%). More recently, however, Bolivia has also reported the discovery of new lithium resources. World production in 2016 amounted to approximately 35,000 tons. In the case of lithium production, however, things did not remain the same as resources. Australia was the first producer with 14,300 t, followed closely by Chile with 12,000 t, then Argentina with 5700 t and China with only 2000 t. brine basins, Australia extracts them from hard rock mines most of which are exported to China in the form of spodumene. Today's lithium demand has exceeded 32,000 tons annually, of which about a third is for lithium-ion batteries and accumulators and only a quarter for the manufacture of glass along with silicon. A number of minor applications, including nuclear power, represent only a small part of demand today including lithium-7, but very soon the situation will change. In 2013, the US Department of Energy planned to reserve $200 \mathrm{~kg}$ of lithium-7 in reserve and is funding research into production methods. The general demand for $\mathrm{Li}-7$ in PWR cooling systems today is only one tonne per year, including the $400 \mathrm{~kg}$ per year for 65 US PWRs (it should be shown that Russia uses a different $\mathrm{pH}$ control process). When MSRs are built, several tons of pure Li-7 will be required in each (approximately $20 \mathrm{t} / 50 \mathrm{~m} 3 \mathrm{LiF}$ with 5 tons Li-7, for each GWe in a single account, 150-400 tons FLiBe with $21-56$ tons $\mathrm{Li}-7$ of another). In this way, here too, the demand for Li-7 could easily reach from 1 ton/year to 250 tons per year and then much higher. It should also be noted that the United States was originally the largest producer of lithium from the late 1950 s to the mid-1980s when the stock was about 42,000 tons of lithium hydroxide. Enrichment with lithium (up to Li-6) led to a large American inventory of both tailings depleted in Li6 (Portsmouth, Ohio and K-25 at Oak Ridge, Tenn) and unprocessed lithium. Most of them, especially Li-7, were then sold on the open market. Lithium-7 production ceased in the United States in 1963, in part due to environmental problems and the mercury OHS that was used for enrichment (Petrescu and Petrescu, 2020a). Lithium could become a basic adjunct to future fission, fusion, or combined nuclear power (Petrescu and Petrescu, 2020a-d; Petrescu et al., 2020) as well as fuel storage (the hydrogen fuel storage) for aerospace propulsion (Duan et al., 2019). Lithium can also be used in the materials industry for sandwich structures along with other components (Aversa et al., 2017a-b; 2017; 2016a-b; Duan et al., 2019; Uhlenbeck and Goudsmit, 1925; Wichmann, 1983; Tomonaga,1997; Mânzatu, 1969; Halliday and Robert, 1966; Kramer, 2011; Krane and Halliday, 1988; Moses et al., 2009; Petrescu and Calautit, 2016a-b; Petrescu and Petrescu, 2014; 2018; 2019; Petrescu et al., 2016a-b; 2017a-f; Petrescu, 2012a-b; 2014; 2018; 2019; Shultis and Faw, 2002; Schwochau, 1984). The demand for lithium is constantly increasing.

Companies use this raw material in the manufacture of batteries for electric cars, mobile phones and all kinds of electrical appliances. It started slowly but evolved rapidly, being increasingly used in batteries and accumulators, so that the demand for lithium is growing exponentially while production cannot, meet demand. Strange but predictable phenomena are happening, because new technologies require more and more micro and Nano chips, sensors, actuators and batteries, often the demand is much higher than their chances of occurring. But in lithium, for example, compared to Nano chips or microchips, there is also the problem of the raw material. As we have already shown, Lithium could be found in larger quantities on our planet, but there is no time for that because today's lithium requirements are huge and growing. The production market is dominated by Chile, Argentina and Australia. Today, global demand for lithium carbonate is expected to reach 372,288 tonnes, up from 201,000 tonnes in 2016.Chile's National Mining Commission estimates global production will reach 440,318 tons by 2021.The first metal in Mendeleev's Periodic Table of Elements, lithium is also the lightest, a valuable feature for electronics manufacturers. We do not want to mention the fact that it is increasingly used in medicines, where the demand for lithium is also constantly increasing. Maybe today we should be concerned about the possibility of bringing lithium from the universe, for a moment somewhere closer, so that it does not last long and does not cost us too much. A possible orientation would be to extract lithium from the water of the seas and oceans, where the amount of lithium is huge even if it is found very scattered in the water of the planet's ocean. Technologies could cope with such processes today. A real challenge would be to be able to already produce other types of modern batteries that are no longer based on the lithium element, because the huge demand here is concentrated.

The largest reserves are in the "lithium triangle", in the salt lakes located on the triple border ArgentinaBolivia-Chile, on both sides of the Cordillera Andes. This area has more than half of the world's reserves. The resources are exploited by Argentina and Chile, but not by Bolivia. Other important manufacturers are China, the USA and Canada. Peru recently announced the discovery of a huge lithium and uranium deposit in the Puno region near Lake Titicaca. This could provide a more comfortable break by supplementing world production 
and with the help of new deposits discovered in Peru. However, from now on, humanity must seriously analyze the world situation and take urgent measures to produce modern batteries and accumulators from other materials that do not contain lithium at all, so that we can extract the huge lithium resources from the ocean planetary by modern technologies, possible today, so that the respite period granted by the additional production coming from Peru to be judiciously used by mankind.

It seems that there will be some new reserves of nuclear energy on fission with uranium, but in this area, the planet is much better and can even breathe quietly with the diversity of renewable and sustainable green energy already in play, especially as they continue to multiply.

Chile extracts lithium from the Atacama Desert, one of the richest deposits in the world. The deposit is famous for its high concentration and low level of impurities.

Today with sustainable green energy we are much better than when the first fission nuclear energy of uranium was produced on an industrial scale, it being a necessary evil, because the planetary energy crisis is the one that always haunted humanity causing all kinds of wars, convulsions, struggles, falls, slips in the past. Although today we have implemented many methods of obtaining green energy and they are still growing, until nuclear fusion energy is ready on an industrial scale, controlled, we cannot talk about the elimination of fission energy, but on the contrary, it will be able to be maintained for a longer time, precisely because it saved us from crises and other new wars. Most crises and wars have been caused by major energy crises. With the advent of nuclear fission, they gave way, even though some local struggles still existed, especially for old and new areas with oil and gas reserves. Deep shale gas has also improved the situation, so we can strongly say that today we are much better in terms of energy and peace, resources and how they are managed. The energy towers of solar farms need to be further multiplied, because they have much better final energy efficiency than that of photovoltaics, although they have also been much improved.

Wind and wind energy are still very good but they must be used in control together with other energy sources, such as nuclear, hydro and solar farms.

Major resources still unused are those of wave energy, the tests so far being in fact insignificant in the percentage of world energy obtained, but we hope that they will continue to gain ground as renewable and sustainable energy, cheap, safe, non-hazardous, which can generate quantities huge amount of energy. Because even nuclear fission energy still has an important role in the future, we designed this work, mostly focused on fission nuclear energy, on an industrial scale, based on the element lithium, which used in this way could generate huge energy for humanity, being much more efficiently.

\section{Materials and Methods}

The idea circulated among physicists that in the upper area of the physical elements the fission reaction can be obtained and in the lower one the fusion reaction occurs.

In the presented paper we want to impose another rule, namely the obtaining in the lower part of the physical elements of the fission and fusion nuclear reactions, with the obvious purpose of obtaining free nuclear energy on an industrial scale. The advantages of using the low area of the physical and chemical elements are multiple. For example, in this area there are no spontaneous reactions, nor disintegrations, so the nuclear fuel used will be without radioactivity and usually, the result of the reaction will also be without radioactive components, so there will be no nuclear residues in the reaction radioactive. In this way, no such nuclear residues remain after such reactions that need to be processed or buried somewhere. Basically, this is a huge advantage of the nuclear exploitation of the low-element area. Another immediate advantage is the use of renewable and sustainable fuel, because, in the high area of heavy physical elements, those used as nuclear fuel are already beginning to run out. Here in the low area of the physicochemical elements the elements are found quite frequently naturally, or can be obtained by various methods, so the nuclear fuels in this area are sustainable, which is a second great advantage in the production of nuclear energy on the industrial route.

The third great advantage of using nuclear fuels in the area of low elements (light, low mass) is that nuclear fission or fusion reactions are easily controllable in this area and they have virtually no way to get out of control and produce unwanted (accidental) events.

If we make a short recap we will see three major advantages of using light elements in nuclear fission or fusion reactions in the future, namely the lack of radioactive residues, sufficient sustainable raw materials, a good control of nuclear reactions without the risk of them getting out of control and to generate unwanted, accidental chain reactions.

Nuclear industrial reactions are well developed today, but only in the area of heavy elements, while in the area of light ones, tests are still being made for their controlled production on an industrial scale, not only in the laboratory. This area of light elements has the three great advantages already mentioned, but it has not been practically exploited yet for technical-scientific reasons, there are great problems still unresolved, of a more technical nature. For this reason, we wanted to launch this paper precisely in order to discuss the possible solutions that will help in the future to achieve nuclear reactions of fission, fusion. Next, a review will be made of the fusion or fission nuclear reactions in the area of light elements, which can be taken into account immediately. Of course, these reactions are extremely many, some of them already 
known from the laboratory and others still unknown to us, but here will be mentioned not a few of them, namely the best known and most important.

Obviously, this paper wants to bring great changes in the area of nuclear energy, changes long-awaited, now requiring the realization on an industrial scale of nuclear fission reactions and then fusion, using only light, non-radioactive elements, sustainable elements and which through nuclear reactions will produce additional energy but not radioactive nuclear residues (as happens in the case of reactions obtained with heavy elements).

Today we are at a crossroads, where we have been using nuclear fission energy obtained for 70 years with enriched radioactive heavy elements, an energy that was a necessary evil and which will still be used for a while to complete the other existing energies today renewable and sustainable but also green, usually obtained from water, hydro, solar energy, photovoltaic or by heat from the sun and wind. Unfortunately, we still burn oil, gas and even coal and in this way, we pollute the planet very much and we generate a greenhouse effect with global warming that brings undesirable climate change to the palette. Obviously, in the conditions in which we still burn hydrocarbons, there is no question of the total and immediate elimination of the nuclear fission energy of heavy elements, no matter how polluting and dangerous it may be. There are countries like France that get almost all the energy needed only in this way, although there is a very high sustainable green energy potential of energy obtained from the tide, by building a huge plant that takes over the energy of the tides and when they penetrate the ground and their withdrawal. A huge plant of this kind could have provided the needs of the whole of Europe. France is not willing to allocate the necessary funds to such a huge enterprise, which, however, also occupies a much larger space, as long as it can provide the necessary energy entirely through nuclear fission of heavy elements.

The very existence in the world of power plants that still burn gas, oil, diesel and especially coal, indicates that we still need a lot of nuclear energy for the fission of heavy elements, but the beginning of their gradual replacement with light ones is already necessary and this is the main reason why this work was prepared.

The lighter nuclear energy of light elements will be able to penetrate very quickly the current energy industrial zone and will complete this zone in a superior way, for an indefinite period of time. Let's not forget that the efficiency of photovoltaics is still low, they produce almost as much energy as is consumed for their manufacture, so in reality, the total energy efficiency of photovoltaics has been negative for a long time and only now tends to zero, but a plus still can't bring, we using them only out of the desire to have clean energy in certain areas.

Let's not forget that the bioenergy in the country also has a lot of problems and it doesn't have a real high efficiency either.

Hydrocarbon fuels are still burning, not only oil, gas and coal but also bio, from field crops, so we still have a total lack of normal energy worldwide. Under these conditions, it is normal to continue to use nuclear energy as we currently have it, but it is even more natural to try to improve nuclear energy.

The fusion energy of light elements on an industrial scale, as in the sun, is almost ready and will bring with it major changes to the planet and a great relief to the planetary energy system. The paper proposes that in addition to its study, to try the realization of nuclear fission energy of light elements, clean, sustainable, friendly energy.

In some future works, the authors will complete this proposed new energy with a much higher one, that of the energy obtained by the annihilation of opposing particles, matter with antimatter. Here, too, international progress is already remarkable, so that we can already discuss these future technical possibilities, which would otherwise have arisen in some SF aspects.

The paper briefly presents an original theoretical method that aims to obtain nuclear energy by forcing a good efficiency of the reaction between lithium and hydrogen by accelerating hydrogen nuclei to energies high enough to cover the kinetic energy of an accelerated proton so that it to overcome the potential nuclear energy barrier of rejection between the charges of the same kind of lithium nucleus and proton, considering the most unfavorable situation possible when the proton approaches the lithium nucleus to its positively charged part through its three protons.

Normally the energy required to overcome the positive potential barrier is slightly lower than that of the extreme situation imagined by the authors so that if we bombard lithium bars with hydrogen protons accelerated to the potential proposed in the paper the chances of lithium-proton nuclear reaction to occur efficiently are very high. It is hoped that in this way a general laboratory reaction, lithium-proton, can be performed continuously with good efficiency in repeatable industrial processes so that such a nuclear reaction itself generates enough energy (anyway more than that injected), or (at least) to constitute one method of initiating the classical nuclear fusion reaction between hydrogen isotopes 2 (deuterium) on an industrial scale. 
The most used nuclear reaction of lithium is the one in Eq. 1, when it reacts with a neutron, being also the most desired because it is known that neutrons have a great reaction power and they are in fact the ones who start almost all the main reactions both in fission as well as in fusion. Their problem is that they cannot accelerate directly as they do the protons or electrons, which is why they can only be accelerated indirectly from other reactions from which neutrons result with high energy:

${ }_{3}^{6} \mathrm{Li}+{ }^{1} \mathrm{n} \rightarrow{ }_{1}^{3} \mathrm{~T}+{ }_{2}^{4} \mathrm{He}+4.784 \mathrm{MeV}$

When we have to perform a classical fusion nuclear reaction in which deuteron is used as fuel, reactions described by Eq. 2 and 3, occur as an intermediate element and tritium (the third isotope of hydrogen) which also reacts with deuterium (Eq. 4 and 5), but also with itself (the nuclear reaction in Eq. 6), or with helium 3 in two different ways (Eq. 7 and 8), where helium three can also react and with itself (Eq. 9):

$$
\begin{aligned}
& { }_{1}^{2} \mathrm{D}+{ }_{1}^{2} \mathrm{D} \rightarrow{ }_{1}^{3} \mathrm{~T}+1.01 \mathrm{MeV}+{ }_{1}^{1} \mathrm{H}+3.02 \mathrm{MeV} \\
& ={ }_{1}^{3} \mathrm{~T}+{ }_{1}^{1} \mathrm{H}+4.03 \mathrm{MeV} \\
& { }_{1}^{2} \mathrm{D}+{ }_{1}^{2} \mathrm{D} \rightarrow{ }_{2}^{3} \mathrm{He}+0.82 \mathrm{MeV}+{ }^{1} n+2.45 \mathrm{MeV} \\
& ={ }_{2}^{3} \mathrm{He}+{ }^{1} n+3.27 \mathrm{MeV}
\end{aligned}
$$

Fusion reaction may occur and between a nucleus of Deuterium and one of Tritium (Eq. 4) and this fusion nuclear reaction may be produced more easily than one between two deuterons (Eq. 2 and 3):

$$
\begin{aligned}
& { }_{1}^{2} \mathrm{D}+{ }_{1}^{3} \mathrm{~T} \rightarrow{ }_{2}^{4} \mathrm{He}+3.5 \mathrm{MeV}+{ }^{1} n+14.1 \mathrm{MeV} \\
& ={ }_{2}^{4} \mathrm{He}+{ }^{1} n+17.6 \mathrm{MeV}
\end{aligned}
$$

An important nuclear reaction may be produced between a nucleus of Deuterium and an isotope of Helium (Eq. 5):

$$
\begin{aligned}
& { }_{1}^{2} \mathrm{D}+{ }_{2}^{3} \mathrm{He} \rightarrow{ }_{2}^{4} \mathrm{He}+3.6 \mathrm{MeV}+{ }_{1}^{1} \mathrm{H}+14.7 \mathrm{MeV} \\
& ={ }_{2}^{4} \mathrm{He}+{ }_{1}^{1} \mathrm{H}+18.3 \mathrm{MeV} \\
& { }_{1}^{3} \mathrm{~T}+{ }_{1}^{3} \mathrm{~T} \rightarrow{ }_{2}^{4} \mathrm{He}+2 \cdot{ }^{1} \mathrm{n}+11.3 \mathrm{MeV} \\
& { }_{2}^{3} \mathrm{He}+{ }_{1}^{3} \mathrm{~T} \rightarrow{ }_{2}^{4} \mathrm{He}+{ }_{1}^{1} \mathrm{H}+{ }^{1} \mathrm{n}+12.1 \mathrm{MeV} \\
& { }_{2}^{3} \mathrm{He}+{ }_{1}^{3} \mathrm{~T} \rightarrow{ }_{2}^{4} \mathrm{He}+4.8 \mathrm{MeV}+{ }_{1}^{2} \mathrm{D}+9.5 \mathrm{MeV} \\
& ={ }_{2}^{4} \mathrm{He}+{ }_{1}^{2} \mathrm{D}+14.3 \mathrm{MeV}
\end{aligned}
$$

$$
{ }_{2}^{3} \mathrm{He}+{ }_{2}^{3} \mathrm{He} \rightarrow{ }_{2}^{4} \mathrm{He}+2 \cdot{ }_{1}^{1} \mathrm{H}+12.9 \mathrm{MeV}
$$

It can be seen that all these nuclear reactions also produce energy.

Lithium with deuterium can still generate four other important reactions (Eq. 10-13):

${ }_{1}^{2} \mathrm{D}+{ }_{3}^{6} \mathrm{Li} \rightarrow 2 \cdot{ }_{2}^{4} \mathrm{He}+22.4 \mathrm{MeV}$

${ }_{1}^{2} \mathrm{D}+{ }_{3}^{6} \mathrm{Li} \rightarrow{ }_{2}^{3} \mathrm{He}+{ }_{2}^{4} \mathrm{He}+{ }^{1} n+2.56 \mathrm{MeV}$

${ }_{1}^{2} \mathrm{D}+{ }_{3}^{6} \mathrm{Li} \rightarrow{ }_{3}^{7} \mathrm{Li}+{ }_{1}^{1} \mathrm{H}+5.0 \mathrm{MeV}$

${ }_{1}^{2} \mathrm{D}+{ }_{3}^{6} \mathrm{Li} \rightarrow{ }_{4}^{7} \mathrm{Be}+{ }^{1} \mathrm{n}+3.4 \mathrm{MeV}$

The fission of lithium 7 in helium performed by Cockcroft and Walton in 1932 was the first artificial fission reaction, in this case, induced by proton bombardment (Eq. 14):

${ }_{3}^{7} \mathrm{Li}+{ }_{1}^{1} \mathrm{H} \rightarrow 2 \cdot{ }_{2}^{4} \mathrm{He}+17 \mathrm{MeV}$

Lithium 6 can react and with hydrogen $=$ Protium $(\mathrm{a}$ proton; Eq. 15) or with an isotope of $\mathrm{He}$ (Eq. 16):

$$
\begin{aligned}
& { }_{1}^{1} \mathrm{H}+{ }_{3}^{6} \mathrm{Li} \rightarrow{ }_{2}^{4} \mathrm{He}+1.7 \mathrm{MeV}+{ }_{2}^{3} \mathrm{He}+2.3 \mathrm{MeV} \\
& ={ }_{2}^{4} \mathrm{He}+{ }_{2}^{3} \mathrm{He}+4.0 \mathrm{MeV} \\
& { }_{2}^{3} \mathrm{He}+{ }_{3}^{6} \mathrm{Li} \rightarrow 2 \cdot{ }_{2}^{4} \mathrm{He}+{ }_{1}^{1} \mathrm{H}+16.9 \mathrm{MeV}
\end{aligned}
$$

If both reactions 1 and 2 take place successively, the hydrogen nuclear transforms the lithium 6 into helium and then it recovers as if it had not intervened in the two reactions. Basically, although we introduce hydrogen and lithium, it obtains helium and a lot of energy together with the hydrogen that recovers, being able to participate in another reaction with the lithium, but in fact, some new accelerated protons is required to be introduced over the remaining lithium bar so that the reaction continues at a required rate.

Basically in this study, we want to stop at these last two nuclear fission reactions, 15-16.

\section{New Theory}

The basic idea is to achieve the nuclear fission reaction of lithium 6 by bombarding it with accelerated protons, which if they have a calculated minimum 
speed, will be able to produce a good efficiency of the nuclear fission reaction.

The material used as nuclear fuel is lithium organized in the form of metal bars that will be introduced inside the nuclear fission reactor. The more bars introduced and the deeper, the reaction tends to increase if the bombing protons also have sufficient energy. If a good reaction yield is reached, it will be kept as constant as possible by reducing the amount of bombardment protons and maintaining them at a certain convenient flow throughout the nuclear fission reaction and when the reaction will tend to accelerate too much, to keep it under control, we must reduce the amount of accelerated protons introduced into the reaction chamber and or simultaneously remove the lithium bars from the reaction chamber, but they can be removed completely from the reactor if necessary, as well as the protons of the bombing that can also be completely stopped from penetrating the reaction chamber.

The nucleus of a lithium atom 6 has approximately the shape of Fig. 1, containing three protons and three neutrons.

Considering the most unfavorable case when the bombardment proton approaches the lithium nucleus 6 on the side containing its three positively charged protons, the bombardment proton must first be accelerated to kinetic energy at least equal to the potential repulsion energy between the three lithium 6 protons and the intruder proton (Fig. 2 and relations $17-$ 18) (Petrescu and Petrescu, 2020a-d):

$U_{\min p}[J]=\frac{1}{4 \pi \varepsilon_{0}} \cdot \frac{q_{3 p} \cdot q_{p}}{d}$

The kinetic energy of the accelerated proton is also written in the form (18):

$$
E_{c \min p}[J]=\frac{c^{2} \cdot m_{0 p}}{2} \cdot \frac{\beta^{2}}{\sqrt{1-\beta^{2}}}
$$

Equating the two expressions (17 and 18) we obtain the first expression of the size of the accelerated proton radius (19), where the diameter $d$ of the proton will be replaced by twice the radius of the proton, eps $s_{0}$ being the permissive constant, $c$ the speed of light in vacuum, $m_{0 p}$ the rest mass of the proton, $q_{p}$ the charge of the proton and beta the ratio between the speed of the accelerated proton and the speed of light v/c (Petrescu and Petrescu, 2020 a-d):
$R_{p 1}[m]=\frac{1}{4 \pi \varepsilon_{0} \cdot c^{2} \cdot m_{0 p}} \cdot q_{3 p} \cdot q_{p} \cdot \frac{\sqrt{1-\beta^{2}}}{\beta^{2}}$

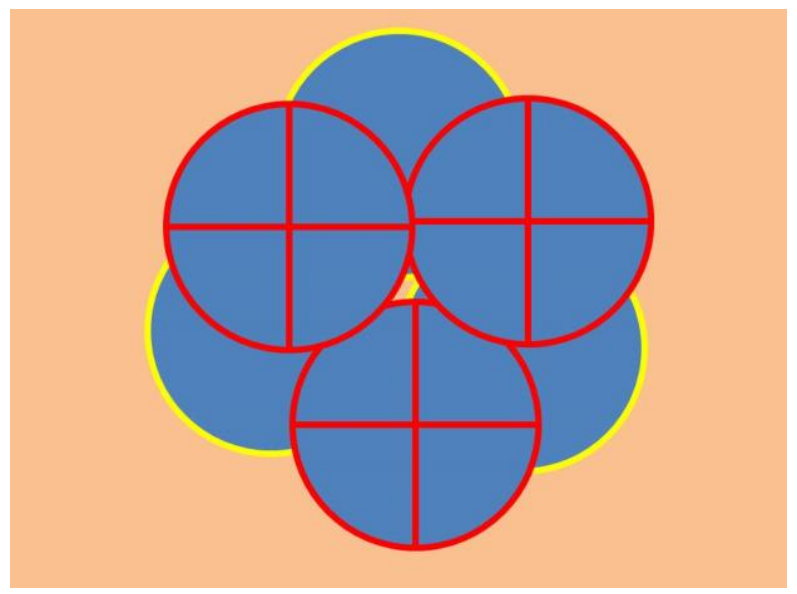

Fig. 1: The nucleus of a lithium atom 6

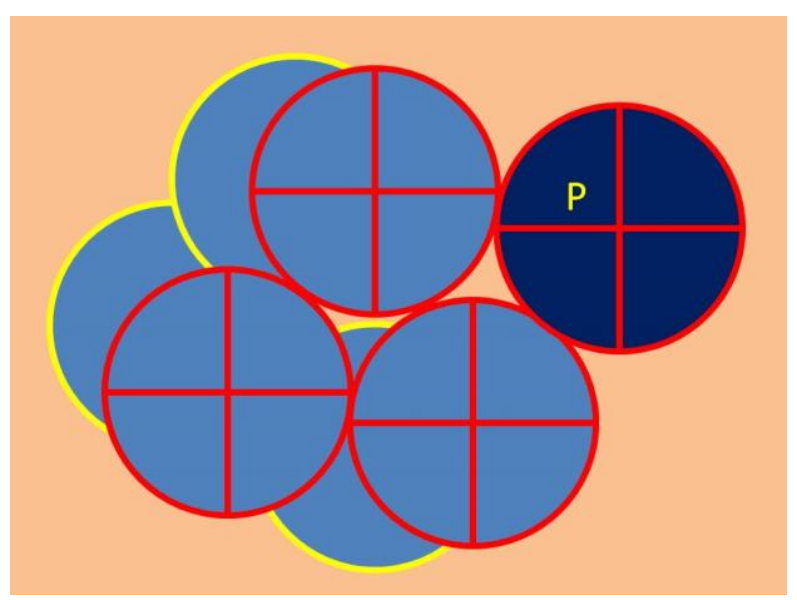

Fig. 2: The nucleus of a lithium atom 6 and the intruder proton

The second ray of the proton is written from the original relation (20) that the authors have already presented in the works (Petrescu and Petrescu, 2020a-d):

$R_{p 2}[m]=\sqrt{\frac{10}{8}} \frac{h}{\pi \cdot c \cdot m_{0 p}} \cdot \frac{\sqrt{1-\beta^{2}} \cdot \sqrt{1-\frac{1}{2} \beta^{2}-\sqrt{1-\beta^{2}}}}{\beta}$

\section{Results}

Solve the system of two nonlinear equations with two unknowns, $R p$ and Beta and obtains the corresponding values: $R_{p}=4.87317 \mathrm{E}-17$ [m]; $\beta=0.3001876$.

Corresponding to these values is immediately determined the speed at which the bombardment proton must circulate and its kinetic energy: 
$v_{p}=89993991.07[\mathrm{~m} / \mathrm{s}]$

$E_{c p}=7.1007 \mathrm{E}-12[\mathrm{~J}]=44319042.93[\mathrm{eV}]=44.32[\mathrm{MeV}]$

It is also possible to introduce accelerated neutrons into the reactor that will be able to start the nuclear fission reaction of lithium six or seven even faster, either by introducing ready-accelerated neutrons or by producing them from protons by bombarding ready-accelerated protons with accelerated electrons so that the electrons that will penetrate the protons can contain enough energy to transform the protons into neutrons (Petrescu and Petrescu, 2020a-d).

The nuclear fusion reaction is generally more difficult to start and maintain and because of this we could use a nuclear fission reaction to initiate the nuclear fusion reaction.

In general, as we have already shown, neutrons are the ones that have the greatest power to initiate nuclear reactions, both in fission and fusion, as well as in the fission reaction needed to initiate fusion, which is why it is good to use all these reactions and accelerated neutrons.

Reaction 1 will be able to take place with a good yield if the neutrons introduced in the reactor will be sufficiently accelerated and thus will be produced in sufficient quantities besides energy and $\mathrm{He} 4$ and the tritium isotopes (absolutely necessary in the industrial terrestrial nuclear fusion reaction, together with broken deuterons from the reaction fuel, heavy water).

This requires that in the fusion nuclear reactor be found in addition to deuterium (heavy water) and lithium bars 6 , which will react with accelerated neutrons and produce energy, $\mathrm{He} 4$ and tritium (Petrescu and Petrescu, 2020a-d).

\section{Reaction between Accelerated Neutrons and Lithium}

It is very good to be able to produce and control on an industrial scale the reaction between accelerated neutrons and Lithium 6 (Eq. 1) because this reaction is very useful not only for obtaining nuclear fission energy from Lithium 6, along with helium4 and tritium but also for to be able to control other nuclear reactions further. Accelerated neutrons can start almost all important nuclear reactions on an industrial scale, both fission and fusion reactions and if fusion reactions are not yet perfectly controllable on an industrial scale, this is due to the lack of accelerated neutrons in nuclear fusion reactors. Tritium obtained from lithium 6 fission under the action of accelerated neutrons is a good fuel for industrial nuclear fusion along with accelerated neutrons and deuterium (heavy water). The following equations can be written (Petrescu and Petrescu, 2020a-d):

$U_{\min n}[J]=\frac{1}{4 \pi \varepsilon_{0}} \cdot \frac{q_{3 p} \cdot q_{2 / 3 p}}{d}$
The kinetic energy of the accelerated neutrons is also written in the form (22):

$$
E_{c \min n}[J]=\frac{c^{2} \cdot m_{0 n}}{2} \cdot \frac{\beta^{2}}{\sqrt{1-\beta^{2}}}
$$

Equating the two expressions (21and 22) one obtains the first expression of the size of the accelerated neutrons radius (23), where the diameter $d$ of the neutron will be replaced by twice the radius of the neutron, eps $s_{0}$ being the permissive constant, $\mathrm{c}$ the speed of light in vacuum, $\mathrm{m}_{0 \mathrm{n}}$ the rest mass of the neutron, $q_{p}$ the charge of the proton and beta the ratio between the speed of the accelerated neutron and the speed of light, v/c (Petrescu and Petrescu, 2020a-d):

$$
R_{n 1}[m]=\frac{1}{4 \pi \varepsilon_{0} \cdot c^{2} \cdot m_{0 n}} \cdot q_{3 p} \cdot q_{2 / 3 p} \cdot \frac{\sqrt{1-\beta^{2}}}{\beta^{2}}
$$

The second ray of the neutron is written from the original relation (24) that the authors have already presented in the works (Petrescu and Petrescu, 2020 a-d):

$R_{n 2}[m]=\sqrt{\frac{10}{8}} \frac{h}{\pi \cdot c \cdot m_{0 n}} \cdot \frac{\sqrt{1-\beta^{2}} \cdot \sqrt{1-\frac{1}{2} \beta^{2}-\sqrt{1-\beta^{2}}}}{\beta}$

Solve the system of two nonlinear equations with two unknowns, $\mathrm{Rn}$ and Beta and obtains the corresponding values: $R_{n}=4.28418 \mathrm{E}-17[\mathrm{~m}] ; \beta=0.2888029$.

Corresponding to these values is immediately determined the speed at which the bombardment neutron must circulate and its kinetic energy:

$\mathrm{V}_{\mathrm{n}}=78764087.8[\mathrm{~m} / \mathrm{s}]$

$\mathrm{E}_{\mathrm{cn}}=5.3846 \mathrm{E}-12[\mathrm{~J}]=33608041.53[\mathrm{eV}]=33.61[\mathrm{MeV}]$

A first observation is that lithium 6 will react correctly with accelerated neutrons each at a minimum of $33 \mathrm{MeV}$, while the reaction of lithium 6 with protons requires accelerated protons with higher energy, namely at least 44 $\mathrm{MeV}$ each.

\section{Production of Accelerated Neutrons}

In order to produce neutrons accelerated to a certain level, we propose in the paper the following original method, namely the protons from which neutrons will be obtained to be already accelerated at least to the level at which it is desired to accelerate the obtained neutrons and the electrons that will bombard the protons with the purpose of their transformation into 
neutrons will, in turn, be accelerated in advance to an appropriate level (Petrescu and Petrescu, 2020a-d). The calculation relations used are written in forms 25-28 (Petrescu and Petrescu, 2020a-d):

$$
U_{\text {mine }}[J]=\frac{1}{4 \pi \varepsilon_{0}} \cdot \frac{q_{e} \cdot q_{1 / 3 e}}{d}
$$

The kinetic energy of the accelerated electrons is also written in the form (26):

$$
E_{c \text { mine }}[J]=\frac{c^{2} \cdot m_{0 e}}{2} \cdot \frac{\beta^{2}}{\sqrt{1-\beta^{2}}}
$$

Equating the two expressions (25 and 26) one obtains the first expression of the size of the accelerated electron radius (27), where the distance $d$ is the sum between the radius of the electron and proton, eps being the permissive constant, $c$ the speed of light in vacuum, $m_{0 e}$ the rest mass of the neutron, $q_{e}$ the charge of the electron and beta the ratio between the speed of the accelerated electron and the speed of light, v/c (Petrescu and Petrescu, 2020a-d):

$$
R_{e 1}[m]=\frac{1}{2 \pi \varepsilon_{0} \cdot c^{2} \cdot m_{0 e}} \cdot q_{e} \cdot q_{1 / 3 e} \cdot \frac{\sqrt{1-\beta^{2}}}{\beta^{2}}-R_{p}
$$

The second ray of the electron is written from the original relation (28) that the authors have already presented in the works (Petrescu and Petrescu, 2020 a-d):

$$
R_{e 2}[m]=\sqrt{\frac{10}{8}} \frac{h}{\pi \cdot c \cdot m_{0 e}} \cdot \frac{\sqrt{1-\beta^{2}} \cdot \sqrt{1-\frac{1}{2} \beta^{2}-\sqrt{1-\beta^{2}}}}{\beta}
$$

Solve the system of two nonlinear equations with two unknowns, Re and Beta and obtains the corresponding values: $\operatorname{Re}=5.52909 \mathrm{E}-14[\mathrm{~m}] ; \beta=0.1826761$.

Corresponding to these values is immediately determined the speed at which the bombardment electron must circulate and its kinetic energy (Petrescu and Petrescu, 2020 a-d):

$$
\begin{aligned}
& \mathrm{v}_{\mathrm{e}}=54764924.71[\mathrm{~m} / \mathrm{s}] \\
& \mathrm{E}_{\mathrm{ce}}=1.38952 \mathrm{E}-15[\mathrm{~J}]=8672.66865[\mathrm{eV}]=8.67[\mathrm{KeV}]
\end{aligned}
$$

\section{Discussion}

The idea has circulated among physicists that in the upper part of the physical elements the fission reaction can be obtained and in the lower part the fusion reaction takes place.

In the paper presented we want to impose another rule, namely obtaining on the basis of the physical elements of nuclear fission and fusion reactions, with the obvious aim of obtaining free nuclear energy on an industrial scale. The advantages of using the low area of the physical and chemical elements are multiple. For example, there are no spontaneous reactions or disintegrations in this area, so the nuclear fuel used will be without radioactivity and usually the result of the reaction will be without radioactive components, so there will be no nuclear residue in the radioactive reaction. In this way, there is no longer such nuclear residue after such reactions that need to be processed or buried somewhere. Basically, this is a huge advantage of low-level nuclear exploitation. Another immediate advantage is the use of renewable and sustainable fuel, because in the high area of heavy physical elements, those used as nuclear fuel are already starting to run out. Here, in the low area of the physicochemical elements, the elements are found quite frequently naturally or can be obtained by different methods, so that the nuclear fuels in this area are sustainable, which is a second great advantage in the production of energy nuclear on the route.

The third great advantage of using nuclear fuels in the area of low elements (light, low mass) is that nuclear fission or fusion reactions are easy to control in this area and have virtually no way to get out of control and produce unwanted (accidental) events.

If we make a brief recap, we will see three major advantages of using light elements in nuclear fission or fusion reactions in the future, namely the lack of radioactive residues, sufficient sustainable raw materials, good control of nuclear reactions without the risk of them be obtained out of control and to generate unwanted, accidental chain reactions.

Nuclear industrial reactions are well developed today, but only in the area of heavy elements, while in the light area, tests are still being done for their controlled production on an industrial scale, not only in the laboratory. This area of light elements has the three great advantages already mentioned, but it has not yet been practically exploited for technical-scientific reasons, there are big problems still unresolved, of a more technical nature. For this reason, we wanted to launch this paper precisely to discuss possible solutions that will help in the future to achieve nuclear reactions of fission, fusion. Then, a review of nuclear fusion or fission reactions in the area of light elements will be made, which can be considered immediately. Of course, these reactions are extremely many, some of them already known in the laboratory and others still unknown to us, but here will be mentioned quite a lot of them, namely the best known and most important.

Obviously, this paper aims to bring great changes in the field of nuclear energy, long-awaited changes, which now require the industrial scale of nuclear 
fission and then fusion reactions, using only light, non-radioactive elements, sustainable elements that will produce nuclear additional energy reactions, but not radioactive nuclear waste (as is the case with heavy element reactions).

Today we are at a crossroads, where we use nuclear fission energy obtained for 70 years with enriched heavy radioactive elements, an energy that was a necessary evil and will be used for a while to supplement other current renewable energies and durable, but also green, usually obtained from water, hydro, solar energy, photovoltaics or heat from the sun and wind. Unfortunately, we still burn oil, gas and even coal and in this way, we pollute the planet a lot and generate a greenhouse effect with global warming, which brings unwanted climate change to the range. Obviously, given that we are still burning hydrocarbons, there is no question of the total and immediate elimination of the nuclear fission energy of heavy elements, no matter how polluting and dangerous it may be. There are countries like France that get almost all the energy needed in this way, although there is a very high sustainable energy potential of tidal energy, by building a huge plant that takes the energy of the tides and when they enter the country and withdraw from them. Such a huge factory could have provided for the needs of the whole of Europe. France is not willing to allocate the necessary funds to such a huge company, which, however, also occupies a much larger space, as long as it can provide all the necessary energy through the nuclear fission of heavy elements.

The very existence in the world of power plants that still burn gas, oil, diesel and especially coal, indicates that we need a lot of nuclear energy for the fission of heavy elements, but the beginning of their gradual replacement with light ones is already necessary and this is the main reason for which this work was prepared.

The lighter nuclear energy of light elements will be able to penetrate very quickly into the current energy industrial zone and will complete this zone in a superior way, for an indefinite period of time. Let's not forget that the efficiency of photovoltaics is still low, they produce almost as much energy as is consumed for their manufacture, so in reality, the total energy efficiency of photovoltaics has been negative for a long time and only now tends to zero, but a plus it still can't bring, we only use them out of the desire to have clean energy in certain areas.
Let's not forget that the bioenergy in the country also has many problems and does not have a real efficiency.

The fusion energy of light elements on an industrial scale, as in the sun, is almost ready and will bring with its major changes on the planet and a great relief of the planetary energy system. The paper proposes that, in addition to his study, to try to realize the energy of nuclear fission of light elements, a clean, sustainable, friendly energy.

In some future works, the authors will complete this proposed new energy with a much larger one, that of the energy obtained by annihilating the opposite particles, matter with antimatter. Here, too, international progress is already remarkable, so that we can already discuss these future technical possibilities, which would otherwise have arisen in some aspects of SF.

The paper briefly presents an original theoretical method that aims to obtain nuclear energy by forcing a good efficiency of the reaction between lithium and hydrogen by accelerating hydrogen nuclei to energies high enough to cover the kinetic energy of an accelerated proton, so as to exceed potential barrier when you reject nuclear energy between charges of the same type of lithium nucleus and proton, given the worst possible situation when the proton approaches the lithium nucleus towards its positively charged side through its three protons.

Normally, the energy required to overcome the potential positive barrier is slightly lower than the extreme situation imagined by the authors, so that if we bombard lithium bars with hydrogen protons accelerated to the potential proposed in the paper, the chances of lithium-proton nuclear reaction increase in fact they seem to be very large. It is hoped that, in this way, a general laboratory reaction, lithiumproton, can be carried out continuously with good efficiency in repeatable industrial processes, so that such a nuclear reaction generates sufficient energy (more than injected anyway) or (at least) be a method of initiating the classical nuclear fusion reaction between isotopes 2 of hydrogen (deuterium) on an industrial scale.

\section{Conclusion}

The paper briefly presents an original method for determining the energy of the lithium 6 bombardment of the protons or neutrons in order to start and sustain the 
fission nuclear reaction at a convenient constant level with good reaction energy efficiency.

The main advantage of the above method is that from the theoretical level it is possible to know with great precision the minimum necessary energy of the bombing proton or neutron, the energy at which the protons (or neutrons) will be accelerated so that, the reaction will start to be efficient.

The relationships used and presented are very precise and original.

The paper opens major perspectives for industrial nuclear fusion processes, with the use of the classic deuterium fuel, because in some fusion nuclear reactors one or more fission reactions are required to determine the start of the fusion reactions. Equations 15 and 16 presented produce in addition to energy and $\mathrm{He} 4$ and the elements Helium 3 and accelerated protons, which in turn will contribute to other nuclear reactions (7-9) that will produce protons, deuterium and accelerated neutrons capable in turn to trigger other nuclear reactions (2-6 and 10-14).

A first observation is that lithium 6 will react correctly with accelerated neutrons each at a minimum of $33 \mathrm{MeV}$, while the reaction of lithium 6 with protons requires accelerated protons with higher energy, namely at least $44 \mathrm{MeV}$ each.

Probably these reactions will require some additional additives so that they can take place massively and constantly at a good yield, but the objective of this paper does not include discussions regarding these additional additives.

The paper tries to highlight aspects regarding the possibility of producing nuclear energy on an industrial scale in optimal conditions, without risks and especially without toxic and radioactive residues, although the reactions are based more on nuclear fission, but are other than the known classics which generated too much radioactive waste.

Basically, the paper proposes to replace the classic nuclear fission reactions that use as enriched uranium fuel and lithium catalyst, with the industrial nuclear fission reaction of lithium (lithium changes from the position of catalyst to that of nuclear fuel), so that its new fission reaction be better controlled, less dangerous and almost free of radioactive waste as is the case with uranium fission.

In the presented paper we want to impose another rule, namely the obtaining in the lower part of the physical elements of the fission and fusion nuclear reactions, with the obvious purpose of obtaining free nuclear energy on an industrial scale.

The advantages of using the low area of the physical and chemical elements are multiple. For example, in this area there are no spontaneous reactions, nor disintegrations, so the nuclear fuel used will be without radioactivity and usually, the result of the reaction will also be without radioactive components, so there will be no nuclear residues in the reaction radioactive. In this way, no such nuclear residues remain after such reactions that need to be processed or buried somewhere. Basically, this is a huge advantage of the nuclear exploitation of the low-element area. Another immediate advantage is the use of renewable and sustainable fuel, because, in the high area of heavy physical elements, those used as nuclear fuel are already beginning to run out. Here in the low area of the physicochemical elements the elements are found quite frequently naturally, or can be obtained by various methods, so the nuclear fuels in this area are sustainable, which is a second great advantage in the production of nuclear energy on the industrial route.

The third great advantage of using nuclear fuels in the area of low elements (light, low mass) is that nuclear fission or fusion reactions are easily controllable in this area and they have virtually no way to get out of control and produce unwanted (accidental) events.

If we make a short recap we will see three major advantages of using light elements in nuclear fission or fusion reactions in the future, namely the lack of radioactive residues, sufficient sustainable raw materials, a good control of nuclear reactions without the risk of them getting out of control and to generate unwanted, accidental chain reactions.

Nuclear industrial reactions are well developed today, but only in the area of heavy elements, while in the area of light ones, tests are still being made for their controlled production on an industrial scale, not only in the laboratory. This area of light elements has the three great advantages already mentioned, but it has not been practically exploited yet for technical-scientific reasons, there are great problems still unresolved, of a more technical nature. For this reason, we wanted to launch this stud precisely in order to discuss the possible solutions that will help in the future to achieve nuclear reactions of fission, fusion. Next, a review will be made of the fusion or fission nuclear reactions in the area of light elements, which can be taken into account immediately. Of course, these reactions are extremely many, some of them already known from the laboratory and others still unknown to us, but here will be mentioned not a few of them, namely the best known and most important.

Obviously, this study wants to bring great changes in the area of nuclear energy, changes long-awaited, now requiring the realization on an industrial scale of nuclear fission reactions and then fusion, using only light, non-radioactive elements, sustainable elements and which through nuclear reactions will produce additional energy but not radioactive nuclear residues (as happens in the case of reactions obtained with heavy elements).

\section{Acknowledgement}

This text was acknowledged and appreciated by Dr. Veturia CHIROIU Honorific member of Technical 
Sciences Academy of Romania (ASTR) Ph.D. supervisor in Mechanical Engineering.

\section{Funding Information}

Research contract: Contract number 36-5-4D/1986 from 24IV1985, beneficiary CNST RO (Romanian National Center for Science and Technology) Improving dynamic mechanisms internal combustion engines.

! All these matters are copyrighted!

Copyrights:

1. New Aircraft (New Ionic or Beam Engines): no. 548 of 22-04-2010 [cgiywDssin], Aerospace Engineering

2. Some Few Specifications About the Doppler Effect to the Electromagnetic Waves: 636 of 28-05-2010 [iEtcaouxxA], physics

3. Presenting an Atomic Model and Some Possible Applications in LASER Field: nr. 639 of 29-05-2010 [yncngrotfo], physics

4. Some Applications in LASER Field: no. 718 of 0907-2010 [xeujouincC], physics

5. The Energies of Today and Tomorrow: nr. 819 of 3009-2010 [kbHquxwykr], energy engineering

6. Obtaining Energy by the Annihilation of the Matter with Antimatter - The Battle for Energy: nr. 1068 of 13.03.2011 [GfEqpGDzeh], Energy Engineering

\section{Author's Contributions}

All the authors contributed equally to prepare, develop and carry out this manuscript.

\section{Ethics}

This article is original and contains unpublished material. Authors declare that are not ethical issues and no conflict of interest that may arise after the publication of this manuscript.

\section{References}

Aversa, R., Parcesepe, D., Petrescu, R. V., Chen, G., Petrescu, F. I., Tamburrino, F., \& Apicella, A. (2016a). Glassy amorphous metal injection molded induced morphological defects. American Journal of Applied Sciences, 13(12). doi.org/10.3844/ajassp.2016.1476.1482

Aversa, R., Tamburrino, F., Petrescu, R. V., Petrescu, F. I., Artur, M., Chen, G., \& Apicella, A. (2016b). Biomechanically inspired shape memory effect machines driven by muscle like acting NiTi alloys. American Journal of Applied Sciences, 13(11), 1264-1271. doi.org/10.3844/ajassp.2016.1264.1271
Aversa, R., Petrescu, R. V. V., Apicella, A., Petrescu, F. I. T. (2017a). Nano-Diamond Hybrid Materials for Structural Biomedical Application, American Journal of Biochemistry and Biotechnology, 13(1):34-41. doi.org/10.3844/ajbbsp.2017.34.41

Aversa, R., Petrescu, R. V., Apicella, A., Kozaitis, S., Abu-Lebdeh, T., Akash, B., \& Petrescu, F. I. (2017b). Triton for nuclear fusion. American Journal of Engineering and Applied Sciences, 10(4). doi.org/10.3844/ajeassp.2017.992.1000

Duan, Y., Zhang, H., Sfarra, S., Avdelidis, N. P., Loutas, T. H., Sotiriadis, G., ... \& Maldague, X. P. (2019). On the use of infrared thermography and acousto-ultrasonics NDT techniques for ceramiccoated sandwich structures. Energies, 12(13), 2537. doi.org/10.3390/en12132537.

D., Halliday, R. Robert, 1966. Physics, Part II. 1st Edn., John Wiley and Sons, Inc., New York.

Kramer, D. (2011). DOE looks again at inertial fusion as a potential clean-energy source. Physics today, 64(3), 26. doi.org/10.1063/1.3563814.

Krane, K. S., \& Halliday, D. (1988). Introductory nuclear physics (Vol. 465). New York: Wiley. ISBN-10: $047180553 \mathrm{X}, \mathrm{pp}: 864$.

Lithium Occurrence. (2009). Institute of Ocean Energy, Saga University, Japan. Archived from the original on 2 May 2009.

https://web.archive.org/web/20090502142924/http:// www.ioes.saga-u.ac.jp/ioesstudy/li/lithium/occurence.html

Mânzatu, I. (1969). Polarization and orientation in nuclear physics: Quantum basics of spinal polarization.

Moses, E. I., Boyd, R. N., Remington, B. A., Keane, C. J., \& Al-Ayat, R. (2009). The National Ignition Facility: Ushering in a new age for high energy density science. Physics of Plasmas, 16(4), 041006. doi.org/10.1063/1.3116505.

Petrescu, F. I., \& Calautit, J. K. (2016a). About nano fusion and dynamic fusion. American Journal of Applied Sciences, 13(3). doi.org/10.3844/ajassp.2016.261.266

Petrescu, F. I., \& Calautit, J. K. (2016b). About the light dimensions. American Journal of Applied Sciences, 13(3). https://doi.org/10.3844/ajassp.2016.321.325

Petrescu, F. I., \& Petrescu, R. V. (2014). Nuclear green energy. IJAP, 10(1), 3-14. http://iraqiphysicsjournal.com/wpcontent/uploads/2012/11/3-14.pdf

Petrescu, N., \& Petrescu, F. I. (2018). Elementary structure of matter can be studied with new quantum computers. American Journal of Engineering and Applied Sciences, 11(2), 1062-1075. doi.org/10.3844/ajeassp.2018.1062.1075

Petrescu, F. I. T., \& Petrescu, R. V. V. (2019). Nuclear hydrogen structure and dimensions. International Journal of Hydrogen Energy, 44(21), 10833-10837. 
doi.org/10.1016/j.ijhydene.2019.02.140

Petrescu, F. I., Apicella, A., Petrescu, R. V., Kozaitis, S., Bucinell, R., Aversa, R., \& Abu-Lebdeh, T. (2016a). Environmental protection through nuclear energy. American Journal of Applied Sciences, 13(9), 941-946. doi.org/10.3844/ajassp.2016.941.946

Petrescu, R. V., Aversa, R., Apicella, A., Li, S., Chen, G., \& Petrescu, F. I. (2016b). Something about electron dimension. American Journal of Applied Sciences, 13(11), 1272-1276. doi.org/10.3844/ajassp.2016.1272.1276

Petrescu, R. V., Aversa, R., Li, S., Bucinell, R., Kozaitis, S., Abu-Lebdeh, T., ... \& Petrescu, F. I. (2017a). Electron dimensions. American Journal of Engineering and Applied Sciences, 10(2), 584-602. doi.org/10.3844/ajeassp.2017.584.602

Petrescu, R. V., Aversa, R., Kozaitis, S., Apicella, A., Petrescu, F. I. T., (2017b). Deuteron Dimensions, American Journal of Engineering and Applied Sciences, 10(3) doi.org/10.3844/ajeassp.2017.649.654

Petrescu, R. V., Aversa, R., Kozaitis, S., Apicella, A., \& Petrescu, F. I. (2017c). Some proposed solutions to achieve nuclear fusion. American Journal of Engineering and Applied Sciences, 10(3). doi.org/10.3844/ajeassp.2017.703.708

Petrescu, R. V., Aversa, R., Kozaitis, S., Apicella, A., \& Petrescu, F. I. (2017d). The quality of transport and environmental protection, part I. American Journal of Engineering and Applied Sciences, 10(3), 738-755. doi.org/10.3844/ajeassp.2017.709.716

Petrescu, F. I. T., (2014). Nuclear Fusion, Infinite Energy 20(1), 44-47.

Petrescu, R. V. V., Aversa, R., Apicella, A., AbuLebdeh, T. M., \& Petrescu, F. I. T. (2019). A new hypothesis about the nuclear hydrogen structure. Independent Journal of Management \& Production, 10(8), 1749-1771. doi.org/10.14807/ijmp.v10i8.1046.

Petrescu, R. V. V., Machin, A., Fontanez, K., Arango, J. C., Marquez, F. M., \& Petrescu, F. I. T. (2020). Hydrogen for aircraft power and propulsion. international journal of hydrogen energy. doi.org/10.1016/j.ijhydene.2020.05.253

Petrescu, F. I. T., (2012a). Cold nuclear fusion. Plasma Physics and Fusion Technology (S70), INIS 44(16).

Petrescu, F. I. T., (2012b). Cold Nuclear Fusion, Create Space publisher, USA, July 2012, ISBN 978-1-47823426-5, 80 pages, English version.

Petrescu F. I. T., (2018). About the Triton Structure. American Journal of Engineering and Applied Sciences, 11(4):1293-1297. doi.org/10.3844/ajeassp.2018.1293.1297

Petrescu, F. I. T. (2019). About the nuclear particles' structure and dimensions. Computational Particle
Mechanics, 6(2), 191-194. doi.org/10.1007/s40571018-0206-7.

Shultis, J. K., \& Faw, R. E. (2016). Fundamentals of nuclear science and engineering. CRC press. ISBN10: 0824708342, pp; 520.

Petrescu, F. I., Apicella, A., Petrescu, R. V., Kozaitis, S., Bucinell, R., Aversa, R., \& Abu-Lebdeh, T. (2016). Environmental protection through nuclear energy. American Journal of Applied Sciences, 13(9), 941946. doi.org/10.3844/ajassp.2016.941.946. SSRN: https://ssrn.com/abstract=3075403

Petrescu, F. I., (2018) About the Triton Structure. American Journal of Engineering and Applied Sciences, 2018, 11 (4):1293.1297. SSRN: https://ssrn.com/abstract=3306826

Aversa, R., Petrescu, R. V., Apicella, A., Kozaitis, S., Abu-Lebdeh, T., Akash, B., \& Petrescu, F. I. (2017). Triton for nuclear fusion. American Journal of Engineering and Applied Sciences, 10(4). SSRN: https://ssrn.com/abstract=3092610

Petrescu, R. V., Aversa, R., Kozaitis, S., Apicella, A., \& Petrescu, F. I. (2017a). Some proposed solutions to achieve nuclear fusion. American Journal of Engineering and Applied Sciences, 10(3).

Petrescu, R. V., Aversa, R., Kozaitis, S., Apicella, A., \& Petrescu, F. I. (2017b). Some basic reactions in nuclear fusion. American Journal of Engineering and Applied $\quad$ Sciences, $10(3)$ SSRN: https://ssrn.com/abstract=3074117

Petrescu, R. V., Aversa, R., Kozaitis, S., Apicella, A., \& Petrescu, F. I. (2017c). Some proposed solutions to achieve nuclear fusion. American Journal of Engineering and Applied Sciences, 10(3). SSRN: https://ssrn.com/abstract=3074113

Petrescu, R. V., Aversa, R., Apicella, A., Kozaitis, S., Abu-Lebdeh, T., \& Petrescu, F. I. (2017d). Management of Renewable Energies and Environmental Protection. American Journal of Engineering and Applied Sciences, 10(4), 919-948. SSRN: https://ssrn.com/abstract=3074108

Petrescu, R. V., Petrescu, F. I., Aversa, R., \& Apicella, A. (2017e). Nano energy. https://ssrn.com/abstract=3075477

Petrescu, R. V., Aversa, R., Li, S., Bucinell, R., Kozaitis, S., Abu-Lebdeh, T., ... \& Petrescu, F. I. (2017f). Electron dimensions. American Journal of Engineering and Applied Sciences, 10(2), 584-602. SSRN: https://ssrn.com/abstract=3074107

Petrescu, R. V., Aversa, R., Apicella, A., Li, S., Chen, G., \& Petrescu, F. I. (2016). Something about electron dimension. American Journal of Applied Sciences, 13(11), 1272-1276. doi.org/10.3844/ajassp.2016.1272.1276. SSRN: https://ssrn.com/abstract=3075396

Petrescu, N., \& Petrescu, F. I. (2019a). Free Particle Spin 
Speed. American Journal of Engineering and Applied Sciences. SSRN: https://ssrn.com/abstract=3460752

Petrescu, N., \& Petrescu, F. I. (2019b). Permanent Magnetic Fluids. American Journal of Engineering and Applied Sciences, 2018. SSRN: https://ssrn.com/abstract=3460763

Petrescu, R. V., \& Petrescu, F. I. (2020a). Interaction between an Electron and a Quark Down. Relly Victoria Virgil Petrescu and Florian Ion Tiberiu Petrescu, 431-435.

doi.org/https://doi.org/10.3844/ajeassp.2020.431. 435

Petrescu, R. V., \& Petrescu, F. I. (2020b). Contributions to the Hydrogen Fusion. Relly Victoria Virgil Petrescu and Florian Ion Tiberiu Petrescu, Contributions to the Hydrogen Fusion. American Journal of Engineering and Applied Sciences, 13(3), 477-486.

Petrescu, R. V., \& Petrescu, F. I. (2020c). Interaction Between an Accelerated Electron and a Quark up to Transform the Quark up into a Down Quark, so that the Proton Practically Becomes a Neutron. American Journal of Engineering and Applied Sciences, 13(3), 487-498. doi.org/https://doi.org/10.3844/ajeassp.2020.487.498

Petrescu, R. V., \& Petrescu, F. I. (2020d). A Theory that Wants to Obtain Particles Opposite to Protons, Having a Negative Charge. Relly Victoria Virgil
Petrescu and Florian Ion Tiberiu Petrescu, 523-530. doi.org/https://doi.org/10.3844/ajeassp.2020.523.530

Petrescu, R. V. V., Aversa, R., Apicella, A., Abu-Lebdeh, T. M., \& Petrescu, F. I. T. (2019). A new hypothesis about the nuclear hydrogen structure. Independent Journal of Management \& Production, 10(8), 17491771. SSRN: https://ssrn.com/abstract=

Schwochau, K. (1984). "Extraction of metals from seawater". Inorganic Chemistry. Topics in Current Chemistry. 124. Springer Berlin Heidelberg. pp. 91-133. doi.org/10.1007/3-540-13534-0_3.

Tomonaga, S. I. (1997). The story of spin. University of Chicago Press. ISBN 9780226807942.

Uhlenbeck, GE, \& Goudsmit, S. (1925). Replacement of the hypothesis of non-mechanical compulsion by a requirement regarding the internal behavior of each individual electron. The natural sciences , 13 (47), 953-954. doi.org/10.1007/BF01558878

Wichmann, E. H. (1983). "The Berkeley Physics Quantum Physics Course", vol. IV Didactic and Pedagogical Ed., Bucharest, 1983

World Nuclear Association, (2017). Lithium. https://www.world-nuclear.org/informationlibrary/current-and-future-generation/lithium.aspx.

\section{Nomenclature}

$\mathrm{H}$

Q

c

The permissive constant (the permittivity)

\section{$\mathrm{n}$}

Z

$\mathrm{m} 0[\mathrm{~kg}]$

m0electron

m0proton

m0neutron

m0deuteron

m0triton
$\Rightarrow$ The Planck constant: $\mathrm{h}=6.626 \mathrm{E}-34$ [Js]

$\Rightarrow$ Electrical elementary load: qe $=-1.6021 \mathrm{E}-19[\mathrm{C}] \mathrm{qp}=+1.6021 \mathrm{E}-19[\mathrm{C}]$

$=$ The light speed in vacuum: $\mathrm{c}=2.997925 \mathrm{E}+08[\mathrm{~m} / \mathrm{s}]$
$=$ The principal quantum number (the Bohr quantum number);

$=$ The number of protons from the atomic nucleus (the atomic number);

$\Rightarrow$ The rest mass of one particle

$=9.11 \mathrm{E}-31[\mathrm{~kg}]$

$=1.672621898(21) \mathrm{E}-27[\mathrm{~kg}]$

$=1.674927471(21) \mathrm{E}-27[\mathrm{~kg}]$

$=3.34449 \mathrm{E}-27[\mathrm{~kg}]$

$=5.00827 \mathrm{E}-27[\mathrm{~kg}]$ 